\title{
Relation between alcohol intake, myocardial enzyme activity, and myocardial function in dilated cardiomyopathy Evidence for the concept of alcohol induced heart muscle disease
}

\author{
P J RICHARDSON, A D WODAK, * L ATKINSON, J B SAUNDERS, $\dagger$ \\ D E JEWITT \\ From the Cardiac and Liver Unit, King's College Hospital, London
}

SUMMARY Detailed drinking histories were taken in 38 patients in whom dilated cardiomyopathy was diagnosed by cardiac catheterisation and left ventricular biopsy. On the basis of the drinking history twenty patients were classified as being in an abstinent or light drinking group and eighteen patients as being in a heavy drinking group (daily alcohol intake in excess of $80 \mathrm{~g}$ or cumulative lifetime intake exceeding $250 \mathrm{~kg}$ ). Activities of myocardial creatine kinase, lactate dehydrogenase, $\alpha$ hydroxybutyric dehydrogenase, malic dehydrogenase, and aspartate aminotransferase were all higher in the heavy drinkers and myocardial enzyme activity correlated with cumulative lifetime alcohol intake, maximum daily intake, and recent daily intake. Activities of creatine kinase, $\alpha$ hydroxybutyric dehydrogenase, and malic dehydrogenase correlated with ejection fraction, irrespective of the alcohol intake of the patient. These findings were not altered by exclusion of patients with hypertension.

The results indicate that among patients with dilated cardiomyopathy there is a group characterised by a high alcohol intake and raised myocardial tissue enzymes which supports the concept of alcoholic heart muscle disease as a distinct entity.

Although the association between excessive alcohol consumption and congestive (dilated) cardiomyopathy has long been known, ${ }^{12}$ a causal relation remains controversial. ${ }^{3}$ There are no studies that relate quantitative alcohol intake to myocardial damage, as there are for alcoholic liver disease. ${ }^{45}$ Indeed the clinical diagnosis of alcoholic heart muscle disease merely reflects the coexistence of global myocardial dysfunction in a heavy drinker in whom no other cause for myocardial disease has been found.

Requests for reprints to Dr P J Richardson, Cardiac Department, King's College Hospital, Denmark Hill, London SE5 9RS.

Present addresses: ^Dr A D Wodak, Alcohol and Drug Services, St Vincent's Hospital, Sydney, Australia. †Dr J B Saunders, Department of Medicine, Drug and Alcohol Service, Royal Prince Alfred Hospital, Sydney, Australia.

Accepted for publication 25 March 1986
The development of endomyocardial biopsy has enabled histological assessment of the myocardium during life, but there are no specific histological features for alcoholic heart muscle disease. ${ }^{6}$ More recently, measurement of myocardial enzyme activity by microassay of biopsy specimens has been introduced. ${ }^{78}$ Wide differences in activities of several myocardial tissue enzymes were found among patients with dilated heart disease who were both haemodynamically and histologically indistinguishable. ${ }^{8}$ Preliminary data suggested that enzyme activities were highest in those patients diagnosed as having alcoholic heart muscle disease. ${ }^{9}$

The purpose of the present study was to assess the alcohol intake in a group of patients with dilated cardiomyopathy and to relate alcohol intake to myocardial enzyme activities and to myocardial function in order to establish objective evidence in support of the concept of alcohol induced heart muscle disease. 


\section{Patients and methods}

Seventy nine patients underwent myocardial biopsy over a period of 28 months; 41 had dilated cardiomyopathy. The other patients were diagnosed as having a specific heart muscle disease, including acute or healed myocarditis, ischaemic heart disease (with $>50 \%$ stenosis of two or more vessels), or hypertrophic cardiomyopathy. Thirty eight of the 41 patients with dilated cardiomyopathy were investigated; the other three were not available for interview. No patient had any clinical evidence of abnormal nutrition and thiamine deficiency was excluded. We studied 36 men (aged 29-62 years (mean (SD) $49.5(9.3)$ ) and two women (aged 31 and 49 years). Twenty nine were white, three were Asian, and six were West Indian. Diastolic blood pressure was recorded at the fifth phase of the Korotkoff sounds.

ASSESSMENT OF ALCOHOL INTAKE

Patients were interviewed by one of two clinicians (ADW or JBS) who used a standardised interview schedule, which has previously been described and validated in a study of alcoholic cirrhosis, ${ }^{10}$ to ascertain lifetime alcohol consumption. The evolution of the patient's drinking habits was elicited by reference to key events such as school-leaving and changes in employment. With these as anchor points, questions were asked about the average weekly intake of alcohol, pattern of drinking, and the type of beverage taken during successive periods of a patient's life up to the time of presentation with heart disease. From this information various measures of alcohol intake were considered: $(a)$ duration of drinking when daily alcohol intake exceeded $40 \mathrm{~g}$ and $80 \mathrm{~g},(b)$ the corresponding mean daily intake during these periods, $(c)$ the corresponding cumulative alcohol intake, $(d)$ cumulative lifetime alcohol consumption, $(e)$ maximum daily alcohol intake that was maintained for a period of at least a year, and $(f)$ mean daily alcohol intake in the three months before investigation.

Six consecutive patients in the present study were interviewed on a subsequent occasion by the second observer independently to validate the technique in this group of patients. The intraclass correlation coefficients for the comparisons of cumulative lifetime consumption, duration of drinking $>40 \mathrm{~g}$ alcohol/day, and corresponding cumulative intake for the two observers were $0.91,0.89$, and 0.80 respectively.

CARDIAC CATHETERISATION AND MYOCARDIAL BIOPSY

All patients underwent routine diagnostic catheter- isation including selective coronary arteriography and left ventriculography. The left ventriculograms were obtained in the right anterior oblique projection at $30^{\circ}$. The systolic and diastolic frames were traced so that the left ventricular ejection fraction could be measured with a Summographic digitising table linked to a Commodore computer. The ejection fraction was calculated by application of Simpson's rule. ${ }^{11}$ Coronary arteriography showed that in 30 patients all coronary vessels were free of important narrowing (patency $>50 \%$ ); in eight patients there was stenosis $(>50 \%)$ of one vessel only, but in none was there occlusion of the vessel.

Endomyocardial biopsy samples of the left ventricle were obtained with the King's endomyocardial bioptome and the Cordis long sheath introducer system. An average of four tissue samples were taken from each patient. At least two biopsy specimens were examined by routine light and electron microscopy as previously described. ${ }^{6}$ In 24 patients there was sufficient material for enzyme measurement and this was immediately frozen in liquid nitrogen and stored at $-70^{\circ} \mathrm{C}$.

MYOCARDIAL TISSUE ENZYME MICROASSAY Biopsy samples of approximately $2-5 \mathrm{mg}$ were weighed and homogenised in $0.25 \mathrm{~mol} / 1$ ice cold sucrose. The following enzymes were assayed spectrophotometrically ${ }^{9}$ at $25^{\circ} \mathrm{C}$ under conditions of optimum $\mathrm{pH}$ and substrate concentration: creatine kinase, lactate dehydrogenase, $\alpha$ hydroxybutyric dehydrogenase, malic dehydrogenase, and aspartate aminotransferase. Protein was assayed by the method of Lowry et al, ${ }^{12}$ and enzyme activities are expressed as $\mathrm{mU} / \mathrm{mg}$ of tissue protein; $1 \mathrm{mU}$ corresponds to the hydrolysis of $1 \mu \mathrm{mol}$ of substrate $/ \mathrm{min}$.

\section{OTHER LABORATORY INVESTIGATIONS}

Routine haematological and biochemical tests, including liver function tests and serum $\gamma$ glutamyltransferase measurements were performed on the day of admission.

DATA STORAGE AND STATISTICAL PROCEDURES Data were stored and analysed in a CDC 6600 computer by means of the program suite Statistical Package for the Social Sciences. ${ }^{13}$ The distribution of variables was assessed by calculating the skewness (g3) and kurtosis (g4) and the Kolmogorov-Smirnov statistic $Z$; skewed data were transformed to $\log 10$. Statistical significance was assessed by the $\chi^{2}$ test (with Yates's correction where necessary) and Student's $t$ test. Multiple regression analysis was performed with values for myocardial enzyme activity as the dependent variables; independent variables were 

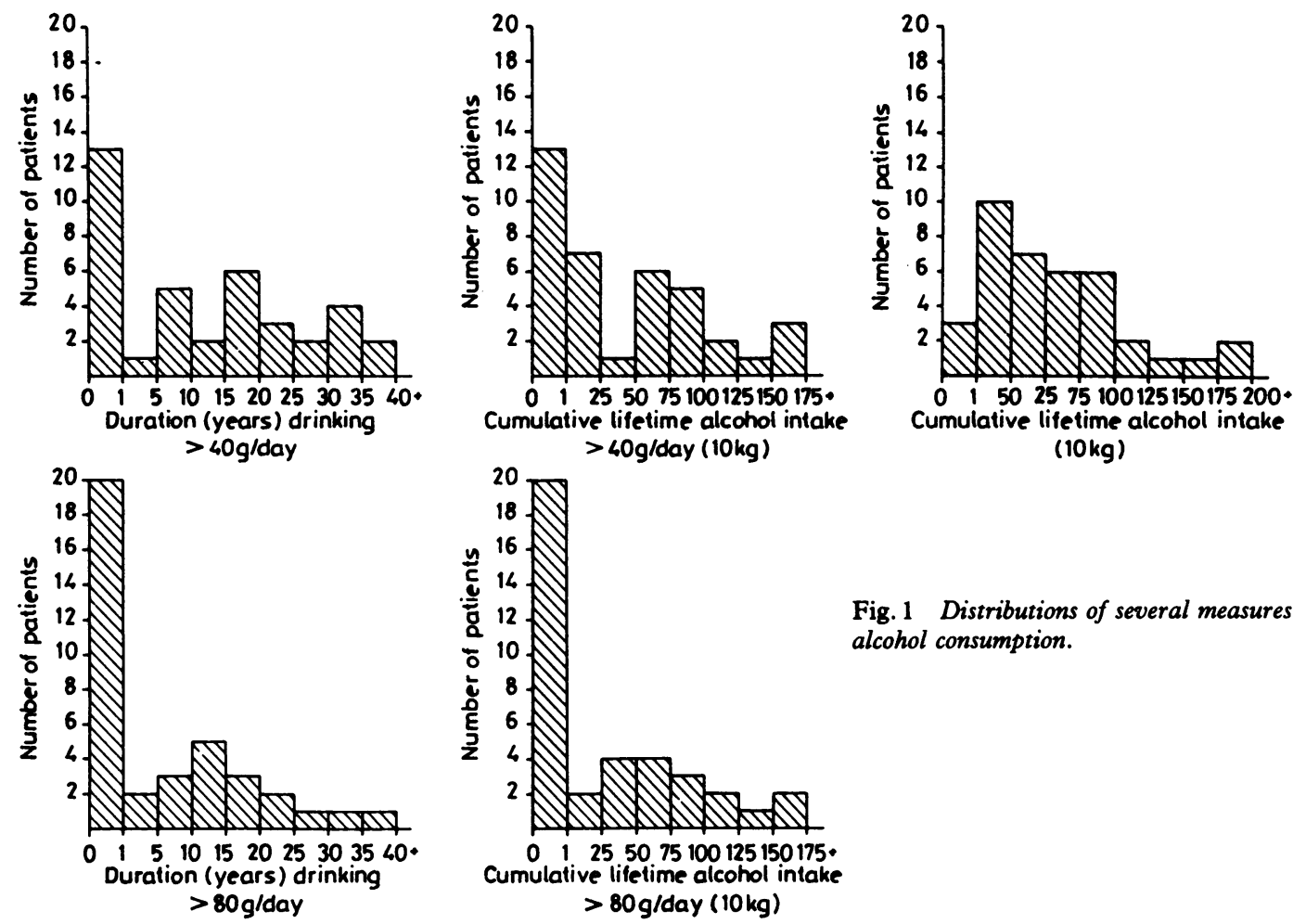

Fig. 1 Distributions of several measures of alcohol consumption.

entered in a stepwise fashion according to the $F$ value for entry into the regression equation.

\section{Results}

DISTRIBUTION OF ALCOHOL CONSUMPTION

Figure 1 shows the distribution of several measures of alcohol consumption in the 38 patients. Three $(8 \%)$ patients were teetotal. The distribution of cumulative lifetime intake was skewed ( $33=1.9$ ) but it was unimodal. Thirteen (34\%) patients had never drunk more than $40 \mathrm{~g}$ alcohol/day and in another seven $(18 \%)$ patients the daily intake had never exceeded $80 \mathrm{~g}$. When cumulative alcohol intake was calculated for periods when drinking exceeded these threshold amounts, a discontinuous distribution was apparent $(z=0.94$ and 1.46 respectively).

While two of the three Asian patients had a cumulative lifetime intake $<250 \mathrm{~kg}$ all six of the West Indian patients had a lifetime alcohol intake $>250 \mathrm{~kg}$.

RELATION OF MYOCARDIAL TISSUE ENZYME ACTIVITY TO ALCOHOL INTAKE There were significant correlations between myo- cardial enzyme activities and cumulative lifetime alcohol consumption, maximum daily intake, and recent daily intake (Table 1 and Fig. 2). Correlation analysis was not performed for the other measures of alcohol intake because of the discontinuities in their distributions. Tissue enzyme activities, except for aspartate aminotransferase, were significantly higher in the heavy drinking group compared with the abstaining or lightly drinking group (Table 2). There was no significant difference in ejection fraction between these two groups.

\section{RELATION BETWEEN MYOCARDIAL ENZYME ACTIVITIES, MYOCARDIAL FUNCTION, AND BLOOD PRESSURE}

The mean (SD) ejection fraction was $42.6(16 \cdot 2)$ and $12(32 \%$ ) patients had an ejection fraction of $<30 \%$, indicating severely impaired myocardial function. There was a correlation between certain myocardial enzyme activities and myocardial impairment as measured by the ejection fraction. The strongest relations were for creatine kinase $(r=0.58, p<0.01)$, $\alpha$ hydroxybutyric dehydrogenase $(r=0.52, p<0.01)$, and malic dehydrogenase $(r=0.44, p<0.05)$. 
Thirteen patients (34\%) had a history of hypertension or were hypertensive (blood pressure $>160 / 95 \mathrm{~mm} \mathrm{Hg}$ ) on admission. When these patients were excluded, the correlation between myocardial enzyme activities and alcohol intake remained significant. Although enzyme activities tended to be higher in hypertensive heavy drinkers than in normotensive heavy drinkers, the differences did not reach statistical significance.

RESULTS OF MULTIPLE REGRESSION ANALYSIS A multiple regression analysis was performed (Table 3) to assess the relations between cumulative alcohol intake, myocardial function (ejection fraction), blood pressure, and myocardial tissue enzyme activities. This confirmed the relation between cumulative alcohol intake and myocardial enzyme activities and showed that ejection fraction was related to the activities of creatine kinase and $\alpha$ hydroxybutyric dehydrogenase independently of alcohol consumption. Neither systolic nor diastolic blood pressure had a significant independent association with tissue enzyme activities.

ALCOHOL INTAKE AND HAEMATOLOGICAL AND BIOCHEMICAL MARKERS OF ALCOHOL CONSUMPTION

There were weak correlations between cumulative lifetime alcohol intake, maximum daily intake, and recent alcohol intake and mean corpuscular volume $(\mathrm{r}=0.32, \mathrm{p}<0.05, \mathrm{r}=0.29, \mathrm{p}<0.05, \quad \mathrm{r}=0.32$, $p<0.05$ respectively). There was no significant correlation between alcohol intake and serum aspartate transaminase, alkaline phosphatase, or $\gamma$ glutamyltransferase activities.

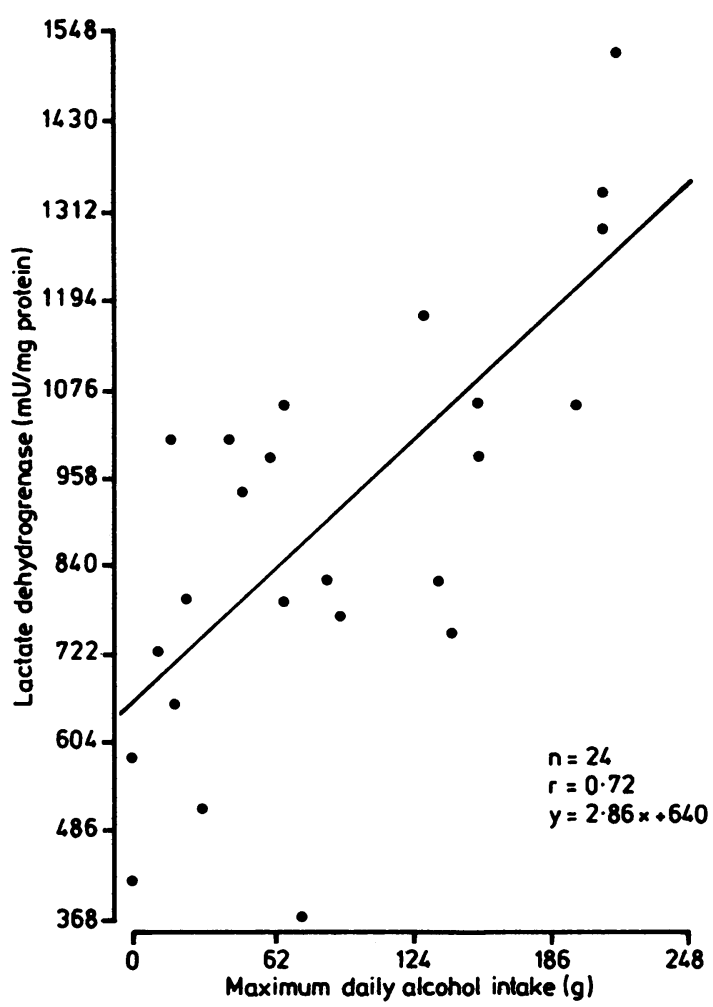

Fig. 2 Relation between myocardial tissue lactate dehydrogenase activity and maximum daily alcohol intake.

Table 1 Results of correlation analysis of myocardial enzyme activities with alcohol intake

\begin{tabular}{|c|c|c|c|c|c|c|}
\hline & \multicolumn{2}{|c|}{$\begin{array}{l}\text { Cumulative lifetime alcohol } \\
\text { intake }\end{array}$} & \multicolumn{2}{|c|}{$\begin{array}{l}\text { Maximum daily alcohol } \\
\text { intake }\end{array}$} & \multicolumn{2}{|c|}{$\begin{array}{l}\text { Recent daily alcohol } \\
\text { intake }\end{array}$} \\
\hline & $r$ & $p$ & $r$ & $p$ & $r$ & $\boldsymbol{p}$ \\
\hline $\begin{array}{l}\text { Creatine kinase } \\
\alpha \text { hydroxybutyric dehydrogenase } \\
\text { Lactate dehydrogenase } \\
\text { Malic dehydrogenase } \\
\text { Aspartate aminotransferase }\end{array}$ & $\begin{array}{l}0.56 \\
0.59 \\
0.68 \\
0.53 \\
0.19\end{array}$ & $\begin{array}{l}<0.01 \\
<0.001 \\
<0.001 \\
<0.01 \\
\text { NS }\end{array}$ & $\begin{array}{l}0.52 \\
0.61 \\
0.72 \\
0.56 \\
0.28\end{array}$ & $\begin{array}{l}<0.01 \\
<0.001 \\
<0.001 \\
<0.01 \\
<0.10\end{array}$ & $\begin{array}{l}0.35 \\
0.49 \\
0.60 \\
0.50 \\
0.26\end{array}$ & $\begin{array}{l}<0.05 \\
<0.01 \\
<0.001 \\
<0.01 \\
\text { NS }\end{array}$ \\
\hline
\end{tabular}

Table 2 Comparison of myocardial enzyme activities (mean (SE)) in abstinent or lightly drinking patients and in heavily drinking patients

\begin{tabular}{|c|c|c|c|}
\hline & $\begin{array}{l}\text { Abstinent or light drinkers } \\
\text { (cumulative intake }<250 \mathrm{~kg}) \\
(n=13)\end{array}$ & $\begin{array}{l}\text { Heavy drinkers } \\
\text { (cumulative intake }>250 \mathrm{~kg}) \\
(n=11)\end{array}$ & $p$ \\
\hline $\begin{array}{l}\text { Creatine kinase (mU/mg protein) } \\
\alpha \text { hydroxybutyric dehydrogenase } \\
\text { Lactate dehydrogenase } \\
\text { Malic dehydrogenase } \\
\text { Aspartate aminotransferase }\end{array}$ & $\begin{array}{c}1674(129) \\
568(39) \\
730(57) \\
2089(185) \\
510(63)\end{array}$ & $\begin{array}{l}2719(226) \\
828(57) \\
1109(69) \\
2976(185) \\
661(61)\end{array}$ & $\begin{array}{l}<0.001 \\
<0.001 \\
<0.001 \\
<0.005 \\
<0.10\end{array}$ \\
\hline
\end{tabular}

*When daily alcohol consumption exceeded $40 \mathrm{~g} /$ day. 
Table 3 Results of multiple regression analysis of the relation between cumulative alcohol intake, ejection fraction, and blood pressure and myocardial enzyme activities

\begin{tabular}{lllll}
\hline Enzyme & & $F$ & $p$ & Multiple r \\
\hline Creatine kinase & Cumulative alcohol intake $(\log 10)$ & 4.59 & $<0.05$ & 0.69 \\
& Ejection fraction & 9.54 & $<0.01$ & 0.58 \\
a hydroxybutyric dehydrogenase & Ciastolic blood pressure & 2.21 & NS & 0.73 \\
& Eumulative alcohol intake (log 10) & 8.09 & $<0.01$ & 0.54 \\
Lactate dehydrogenase & Diastolic blood pressure & 5.86 & $<0.05$ & 0.68 \\
& Cumulative alcohol intake (log 10) & 1.53 & NS & 0.71 \\
Malic dehydrogenase & Ejection fraction & $<0.02$ & 0.65 \\
& Diastolic blood pressure & 2.03 & NS & 0.69 \\
Aspartate aminotransferase & Cumulative alcohol intake (log 10) & $\mathbf{2 . 0 3}$ & NS & 0.73 \\
& Ejection fraction & 3.35 & NS & 0.51 \\
& Diastolic blood pressure & 2.04 & NS & 0.61 \\
& Cumulative alcohol intake (log 10) & 6.42 & $<0.02$ & 0.49 \\
& Ejection fraction & 1.89 & NS & 0.55 \\
\hline
\end{tabular}

\section{Discussion}

There is no clinical or histopathological difference between alcoholic heart muscle disease and dilated cardiomyopathy, ${ }^{614}$ and indeed there are some who do not accept the former as a distinct entity. ${ }^{15}$ In the present study patients with dilated heart muscle disease seemed to consist of two groups defined by their alcohol intake. The bimodal distribution of alcohol intake contrasts with the findings of surveys of alcohol consumption in the general population which show that alcohol intake has a unimodal distribution, with only $4 \%$ of males drinking more than $80 \mathrm{~g} /$ day. ${ }^{1617}$ It is likely that the abstinent and lightly drinking patients represent the general population in terms of drinking $\leqslant 80 \mathrm{~g}$ alcohol/day; higher consumption is implicated in other forms of alcohol induced tissue damage such as cirrhosis of the liver. ${ }^{4}$ The possibility that some light drinkers are especially sensitive to the cardiotoxic effect of alcohol cannot, however, be excluded.

Unlike patients with alcoholic cirrhosis drawn from the same geographical area who drink more spirits (J B Saunders, A D Wodak, R Williams, unpublished observations) the heavy drinkers in our study were predominantly $(83 \%)$ beer drinkers. The reason for this is unknown. Excess consumption of beer, because of its high carbohydrate content, may precipitate beriberi in patients with incipient thiamine deficiency, but none of our patients were thiamine deficient. Cobalt contaminated beer was implicated in the development of heart muscle disease in Canada several years ago, but this problem has now been eliminated. ${ }^{18}$ In previous studies alcoholic heart muscle disease was reported to be confined to men, ${ }^{12}$ and in the present study all the heavy drinkers were men. Again this contrasts with our experience of alcoholic liver disease, to which women are more susceptible. ${ }^{1019}$ No hormonal or other genetically determined factors predisposing to alcoholic heart muscle disease have been identified. ${ }^{20} \mathrm{We}$ found that as in alcoholic liver disease a pattern of continuous drinking rather than episodic drinking seems to be associated with alcoholic heart muscle disease. This may simply reflect the fact that a pattern of unremitting drinking is more likely to result in a higher cumulative alcohol intake than periodic drinking.

It has been suggested that dilated heart muscle disease may be caused by previous hypertension in subjects who have become normotensive after the development of impaired myocardial function (decapitated hypertension). The known association of alcohol use and hypertension may thus be a mechanism for the development of alcoholic heart muscle disease. The results of this study in which the correlations between myocardial enzyme activity and alcohol intake were unaffected by blood pressure do not support the notion of decapitated hypertension as the mechanism for development of alcoholic heart muscle disease.

The increases in myocardial enzyme activities in the heavy drinkers could be adaptive and may reflect chronic exposure to alcohol. Although alcohol can undergo esterification with fatty acid in the myocardium ${ }^{21}$ there is no evidence for appreciable myocardial metabolism of alcohol. In theory patients with alcoholic heart muscle disease may have always had abnormal tissue enzymes concerned with glycolysis and respiration and exposure to alcohol may have precipitated myocardial damage. This seems unlikely in the face of the close correlation between enzyme activity and exposure to alcohol.

Alternatively the enzyme changes may be secondary to myocardial tissue damage caused by an unrelated mechanism. Acute exposure to alcohol increases the concentration of several cardiac enzymes, including malic dehydrogenase, in the 
coronary venous effluent ${ }^{22}$ and this may imply a direct cytotoxic action of ethanol. On this basis, however, it is difficult to explain how myocardial enzyme activities increase in response to chronic alcohol exposure.

The threshold dose of alcohol intake for heart muscle damage cannot be determined directly from studies such as the present one. The risk of developing cirrhosis at various levels of alcohol intake has been determined in epidemiological studies by comparison of the alcohol intake of patients with established cirrhosis with that of healthy age and sex matched patients drawn at random from the same geographical area. For alcoholic heart muscle disease, however, this would be a formidable undertaking in view of the comparative rarity of the condition and the fact that invasive investigation is necessary for a firm diagnosis of specific heart muscle diseases to be made.

Laboratory tests such as mean corpuscular volume, serum aspartate aminotransferase, and $\gamma$ glutamyltransferase have been shown in several studies to be useful markers of excessive alcohol consumption. In the present study, however, although there was a correlation between mean corpuscular volume and alcohol intake it was not of practical use as a diagnostic marker and activities of serum enzymes were similar in the lightly drinking and heavily drinking groups. The best way to discriminate between these two groups seems to be a detailed lifetime drinking history. Serum activities of specific myocardial enzymes such as creatine kinase $\mathrm{MB}$ isoenzyme may prove to be a useful diagnostic tool, though so far this approach has proved to be disappointing. ${ }^{23}$ Myocardial biopsy and measurement of tissue enzyme activity provide useful supportive evidence in favour of an alcoholic aetiology in patients with dilated heart muscle disease.

We thank Dr Roger Williams for allowing us to investigate his patients and Dr Norman Palmer for his helpful comments.

\section{References}

1 Brigden W, Robinson J. Alcoholic heart muscle disease. Br Med f 1964;ii:1283-9.

2 Massumi RA, Rios JC, Gooch AS, Nutter D, De Vita VT, Datlow DW. Primary myocardial diseasereport of 50 cases and review of subject. Circulation 1965;31:19-41.

3 Goodwin JF. Treatment of the cardiomyopathies. $A m \mathcal{F}$ Cardiol 1973;32:341-51.

4 Pequignot G, Chabert C, Eydoux H, Courcoul MA. Augmentation du risque de cirrhose en fonction de la ration d'alcool. Revue de l'Alcoolisme 1974; 20:191-202.
5 Lelbach WK. Organic pathology related to volume and patterns of alcohol use. In: Gibbons RJ, Israel Y, Kalant H, Popham RE, Schmidt W, Smart RD, eds. Research advances in alcohol and drug problems. New York: John Wiley, 1974:93-198.

6 Olsen EGJ. Pathological recognition of cardiomyopathy. Postgrad Med f 1975;51:277-81.

7 Peters TJ, Wells G, Oakley CM, et al. Enzymic analysis of endomyocardial biopsy specimens from patients with cardiomyopathies. Br Heart f 1977;39:1333-9.

8 Richardson PJ, Atkinson L. The measurement of enzyme activities in endomyocardial biopsy samples from patients with cardiomyopathy. In: Sekiguchi M, Olsen EGJ, eds. Cardiomyopathy-clinical, pathological and theoretical aspects. Tokyo: University of Tokyo Press, 1980:149-56.

9 Richardson PJ, Atkinson L, Wodak A. Measurement of enzyme activities in endomyocardial biopsies from patients with congestive (dilated) cardiomyopathy and specific heart muscle disease. $Z$ Kardiol 1982;71:522-6.

10 Saunders JB, Wodak AD, Haines A, et al. Accelerated development of alcoholic cirrhosis in patients with HLA-B8. Lancet 1982;i:1381-4.

11 Reichek N. Echocardiographic assessment of left ventricular hypertrophy. Eur Heart $\mathcal{f}$ 1982;3 (suppl A):49-57.

12 Lowry OH, Roseborough NJ, Farr AL, Randall RJ. Protein measurement with folin-phenol reagent. $\mathcal{F}$ Biol Chem 1951;193:265-75.

13 Nie N, Hull CH, Jenkins JG, Steinbrenner K, Bent DH. Statistical package for the social sciences. New York: McGraw Hill, 1975.

14 Reagan TJ, Haider B. Pathophysiologic effects of ethanol on cardiac tissue. In: Bristow $M$, ed. Drug induced heart disease. North Holland: Elsevier Biomedical Press, 1980:175-89.

15 Oakley C. Diagnosis and natural history of congestive (dilated) cardiomyopathies. Postgrad Med $\mathcal{J}$ 1978;54:440-7.

16 Cartwright AKJ, Shaw SJ, Spratley TA. The relationship between per capita consumption, drinking patterns and alcohol-related problems in a population sample. Addiction 1978;73:237-46.

17 Wilson P. Drinking in England and Wales. London: HMSO, 1980.

18 Morin YL, Foley AR, Martineaux G, Rousad J. Quebec beer-drinker's cardiomyopathy: forty-eight cases. I Can Med Assoc 1967;97:881-904.

19 Saunders JB, Davis M, Williams R. Do women develop alcoholic liver disease more readily than men? $\mathrm{Br} M e d$ f 1981;282:1140-3.

20 Saunders JB, Williams R. The genetics of alcoholism. Alcohol and Alcoholism 1983;18:189-217.

21 Lange LG, Sobel BE. Myocardial metabolites of ethanol. Circ Res 1983;52:470-82.

22 Wendt VE, Wu C, Balcon R, Doty C, Bing RJ. Haemodynamic and metabolic effects of chronic alcoholism in man. Am $\mathcal{F}$ Cardiol 1965;17:175-84.

23 Fink R, Margot DH, Rosalki SB. Detection of alcoholic cardiomyopathy by serum enzyme and isoenzyme determination. Ann Clin Biochem 1979;16:165-6. 